\title{
Comparison of microwave ablation and hepatic resection for hepatocellular carcinoma: a meta- analysis
}

\author{
This article was published in the following Dove Press journal: \\ OncoTargets and Therapy \\ 3 October 2017 \\ Number of times this article has been viewed
}

Background and aims: Hepatic resection (HRN) and microwave ablation (MWA) have significant advantages in treating hepatocellular carcinoma; however, it remains unclear which way produces better outcomes. This meta-analysis of cohort studies compared the treatments in terms of effectiveness and safety.

Methods: Six electronic databases (PubMed, Medline, EMBASE, Web of Science, EBSCO, and The Cochrane Library) were retrieved for studies comparing MWA and HRN. The metaanalysis was conducted based on statement of preferred reporting items for systematic reviews and meta-analyses.

Results: Nine studies met the inclusion criteria, with a total of 1,480 patients. The overall metaanalysis demonstrated no significant difference in overall survival between the MWA group and the HRN group $(\mathrm{HR}=0.98,95 \% \mathrm{CI}=0.76-1.26, P=0.878)$. There was no difference in diseasefree survival between the MWA group and the HRN group $(\mathrm{HR}=1.16,95 \% \mathrm{CI}=0.79-1.71$, $P=0.442$ ). Meanwhile, the meta-analysis demonstrated that MWA was associated with shorter operation time (standardized mean difference $[\mathrm{SMD}]=-1.37,95 \% \mathrm{CI}=-1.92$ to $-0.81, P=0.000$ ), less amount of blood loss in operation ( $\mathrm{SWD}=-1.19,95 \% \mathrm{CI}=-1.76$ to $-0.61, P=0.000$ ), and less complications $(\mathrm{OR}=0.22,95 \% \mathrm{CI}=0.12-0.40, P=0.000)$ than $\mathrm{HRN}$.

Conclusion: In conclusion, our meta-analysis suggests that MWA may be superior to HRN as it is as effective as HRN in terms of overall survival, disease-free survival, tumor recurrence, and is associated with shorter operation time, less amount of blood loss, and fewer complications. Keywords: primary hepatic carcinoma, hepatic resection, microwave ablation, survival analysis

\section{Introduction}

Hepatocellular carcinoma (HCC) is one of the most common cancers and the second major causes of death from cancer worldwide. ${ }^{1,2}$ Hepatic resection (HRN) is considered the first-line treatment for patients with solitary tumors confined to the liver without radiographic evidence of invasion of the vasculature and preserved liver function (normal bilirubin and either hepatic venous pressure gradient $\leq 10 \mathrm{mmHg}$, platelet count $>100,000$, or no varices at endoscopy). ${ }^{3,4}$ However, $80 \%$ of cases were unsuitable for HRN for various reasons such as low rate of early diagnosis, poor residual liver function after surgery, and serious post-operative complications. ${ }^{5}$ As a result, many nonsurgical alternative techniques have been developed, such as radiofrequency ablation (RFA), percutaneous ethanol injection (PEI), acetic acid injection and microwave ablation (MWA). MWA is a promising minimally invasive technique for the treatment of HCC. MWA can be performed safely using percutaneous, laparoscopic, or open 
surgical techniques. MWA aims to induce tumor necrosis by using high frequency ( $>900 \mathrm{MHz}$, usually $2,450 \mathrm{MHz}$ ) electromagnetic energy that determines continuous rotation of dipole molecules in the microwave's oscillating electric field. This vigorous movement of dipoles (mainly water molecules) generates friction and heat, thus inducing tissue death via coagulation necrosis. ${ }^{6}$

MWA is a recent development in the field of tumor ablation $^{7-11}$ and expected to be as effective as RFA for local treatment. Microwave energy is found along the spectrum of electromagnetic radiation, heating the target tissue. ${ }^{11,12} \mathrm{MWA}$ has mainly been used in the People's Republic of China and Japan, ${ }^{13,14}$ but this technology is now gradually becoming popular in Europe and the USA. However, whether it can compete with HRN as the first-line treatment still remains controversial.

Results from published studies have found that the effectiveness and safety of MWA and HRN for HCC were inconsistent. Therefore, it is necessary for us to evaluate the evidence from previous papers that compare the effectiveness and safety of MWA and HRN with meta-analysis of methods to summarize its quantitation.

\section{Methods}

\section{Search strategy}

To identify eligible studies, the main search was conducted in the electronic databases (PubMed, Medline, EMBASE, Web of Science, EBSCO, and The Cochrane Library) from inception through "hepatic resection", "surgical resection", hepatectomy, "microwave ablation", percutaneous microwave coagulation therapy (PMCT), microwave coagulation therapy (MCT), microwave, "liver cancer", "liver neoplasm”, " primary hepatic carcinoma", "hepatocellular carcinoma”, using various combinations of Medical Subject Headings (MeSH) and non-MeSH terms. The date of last search was March 2017. No restriction was set for date of publication. Only human trials and English language studies were considered for inclusion. Literature searches were conducted independently by two authors (Manka Zhang and Jian Zhang). Any discrepancy was resolved by consultation with an investigator (Huimin $\mathrm{Ma}$ ) not involved in the initial procedure.

\section{Inclusion criteria}

We used the following criteria for our research: 1) Studies in which patients were diagnosed with HCC by relevant standards and confirmed by imaging examinations and laboratory tests. 2) Studies comparing the effectiveness of MWA and HRN for HCC. 3) Studies that provided KaplanMeier curves or the specific number of deaths. 4) Randomized controlled trials, comparative and observational studies were considered for inclusion.

\section{Exclusion criteria}

The exclusion criteria were as follows: 1) Small patient researches $(<20)$. 2) Studies in which patients had extrahepatic metastasis. 3) Studies in which patients had other severe liver diseases, any malignancy, variceal bleeding, heart failure, or kidney failure. 4) Studies in which patients received combination of other treatments. 5) Studies in which the follow-up time was $<3$ years.

\section{Outcome measures}

Primary outcomes of interest were indicators of effectiveness, including overall survival (OS), disease-free survival (DFS) and tumor recurrence. Secondary outcomes were indicators of safety, including operation time, loss of blood during operation and the incidence of complications.

\section{Study selection}

Two authors (Manka Zhang and Huimin Ma) independently reviewed the titles and abstracts of all the articles to identify eligible studies. When there were conflicts, they were resolved by the third author (Jian Zhang).

\section{Data extraction and quality assessment}

Data from the included studies were extracted and summarized independently by 2 of the authors (Manka Zhang and Jian Zhang) using a predefined data extraction form. Disagreements were resolved by discussion or consensus with a third reviewer (Huimin Ma). We recorded the following information: general information, including first author, publication date, study design, journal name, region; population characteristics, including number of patients, baseline patient demographics, follow-up time, number of tumors, tumor size, number of patients associated with cirrhosis, tumor stage, and outcomes of research. The methodological quality of cohort studies was assessed by the Newcastle-Ottawa scale, ${ }^{15}$ which consisted of 3 factors: patient selection, comparability of the study groups, and assessment of outcome. A score of 0-9 (allocated as stars) was allocated to each study. Cohort studies achieving 6 or more stars were considered to be of high quality.

\section{Statistical analysis}

This meta-analysis was reported according to the preferred reporting items for systematic reviews and meta-analyses statement. ${ }^{16}$ It was performed in accordance with the recommendations of Cochrane Handbook. Results were entered into the EXCEL form. The Stata (14.0 for Mac, StataCorp, College Station, TX, USA) software was used to estimate the 
pooled HR and 95\% CI for OS and DFS. Engauge Digitizer (version 4.1, M Mitchell, http://markummitchell.github.io/ engauge-digitizer/) software was used to extract survival data from the Kaplan-Meier curves, for studies that had not shown the HR and 95\% CI. ${ }^{17,18}$ Continuous outcomes were expressed as the standardized mean difference (SMD), categorical variables were expressed as OR. All results were reported with $95 \%$ CIs. The heterogeneity was assessed using $I^{2}$ test. According to the Cochrane review guidelines, if severe heterogeneity was present at $I^{2}>25 \%$, the random effect models were chosen, otherwise the fixed effect models were used. Publication biases were evaluated by funnel plot.

\section{Results}

We initially retrieved 1,219 studies, including 183 papers in PubMed, 450 papers in EMBASE, 173 papers in Medline, 209 papers in Web of Science, 185 papers in EBSCO, and 19 papers in The Cochrane Library databases (Figure 1). After exclusion of review articles, papers not in human, case reports, letters, papers not in English, duplicate publications, and papers reporting patients with non-HCC malignant tumors or metastases; 46 potentially eligible studies were identified for further full-text review. We then excluded studies in which patients had received combination treatment or had enrolled not enough patients. Finally, 9 studies were enrolled in the meta-analysis and involved a total of 1,480 patients. ${ }^{19-27}$ The paper characteristics are summarized in Table 1. They were performed in the People's Republic of China $(n=5)$, Japan $(n=4)$. The mean of age ranged from 49.5 to 67.6 years. The male to female ratio in the pooled data was 3.11:1. The results of quality assessment are shown in Table 1 and include 4 papers of 8 stars, 1 paper of 7 stars, and 4 papers of 6 stars.

\section{Primary outcomes \\ Overall survival}

In total, 7 reports with available Kaplan-Meier curves were included for meta-analysis of OS. The overall meta-analysis demonstrated no significant difference in OS between the MWA group and the HRN group $(\mathrm{HR}=0.98,95 \% \mathrm{CI}=0.76-$ 1.26, $P=0.878$ ) (Figure 2). We conducted subgroup analyses

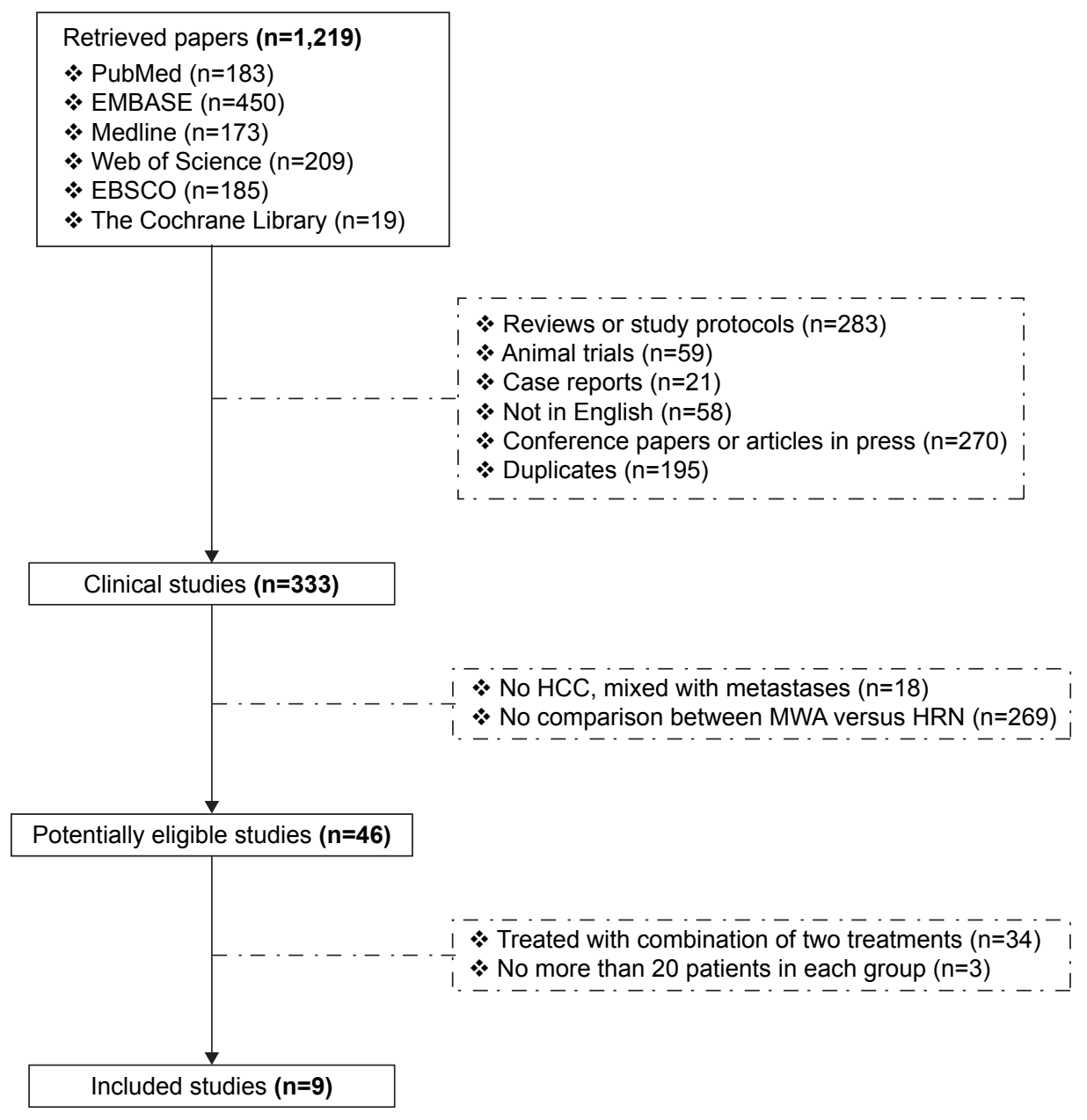

Figure I Flow chart showing selection of studies for meta-analysis.

Abbreviations: MWA, microwave ablation; HRN, hepatic resection; HCC, hepatocellular carcinoma. 
Table I Characteristics of studies included in the meta-analysis

\begin{tabular}{|c|c|c|c|c|c|c|c|}
\hline \multirow[t]{3}{*}{ Authors } & \multirow[t]{3}{*}{ Journal name } & \multirow{3}{*}{$\begin{array}{l}\text { Study } \\
\text { design }\end{array}$} & \multirow[t]{3}{*}{ Region } & \multirow{3}{*}{$\begin{array}{l}\begin{array}{l}\text { Number of } \\
\text { patients }\end{array} \\
\text { (MWA/ } \\
\text { HRN) }\end{array}$} & \multirow{2}{*}{$\begin{array}{l}\text { Age } \\
\text { Mean } \pm \text { SD (years) }\end{array}$} & \multirow{3}{*}{$\begin{array}{l}\text { Sex } \\
(\mathrm{m} / \mathrm{f})\end{array}$} & \multirow{3}{*}{$\begin{array}{l}\text { Follow-up } \\
\text { Duration } \\
\text { (months) }\end{array}$} \\
\hline & & & & & & & \\
\hline & & & & & (MWA/HRN) & & \\
\hline Li et $\mathrm{al}^{24}$ & Hepatol Res & $\begin{array}{l}\text { Retrospective } \\
\text { cohort study }\end{array}$ & $\begin{array}{l}\text { People's Republic } \\
\text { of China }\end{array}$ & $60 / 87$ & $65(45-71) / 63(40-77)$ & $117 / 30$ & $1-60$ \\
\hline $\begin{array}{l}\text { Zhang } \\
\text { et } \mathrm{a}^{20}\end{array}$ & Eur J Surg Oncol & $\begin{array}{l}\text { Retrospective } \\
\text { cohort study }\end{array}$ & $\begin{array}{l}\text { People's Republic } \\
\text { of China }\end{array}$ & $68 / 122$ & $55.4 \pm 9.9 / 49.5 \pm 8.6$ & $168 / 22$ & $9-104$ \\
\hline $\begin{array}{l}\text { Xu and } \\
\text { Zhao }\end{array}$ & Int J Clin Exp Pathol & $\begin{array}{l}\text { Prospective } \\
\text { cohort study }\end{array}$ & $\begin{array}{l}\text { People's Republic } \\
\text { of China }\end{array}$ & $45 / 45$ & $57.9 \pm 3.4 / 58.3 \pm 3.1$ & $66 / 24$ & $1-36$ \\
\hline Shi et $\mathrm{a}^{22}$ & J Gastroenterol Hepatol & $\begin{array}{l}\text { Retrospective } \\
\text { cohort study }\end{array}$ & $\begin{array}{l}\text { People's Republic } \\
\text { of China }\end{array}$ & $117 / 107$ & $56.6 \pm 9.2 / 54.5 \pm 9.9$ & $180 / 44$ & $|-10|$ \\
\hline $\begin{array}{l}\text { Takami } \\
\text { et al }{ }^{26}\end{array}$ & J Hepatobiliary Pancreat Sci & $\begin{array}{l}\text { Retrospective } \\
\text { cohort study }\end{array}$ & Japan & $390 / 34$ & $67.6 \pm 9.1 / 66.1 \pm 7.5$ & $262 / 162$ & $1-184$ \\
\hline $\begin{array}{l}\text { Wang } \\
\text { et al }{ }^{19}\end{array}$ & J Gastrointest Surg & $\begin{array}{l}\text { Retrospective } \\
\text { cohort study }\end{array}$ & $\begin{array}{l}\text { People's Republic } \\
\text { of China }\end{array}$ & $114 / 80$ & $54.82 \pm|| .44 / 57.66 \pm|4.3|$ & $17 \mid / 23$ & $1-96$ \\
\hline $\begin{array}{l}\text { Horigome } \\
\text { et } \mathrm{al}^{21}\end{array}$ & Hepatogastroenterology & $\begin{array}{l}\text { Prospective } \\
\text { cohort study }\end{array}$ & Japan & $29 / 43$ & $65 \pm 5 / 63 \pm 7$ & $55 / 17$ & $1-120$ \\
\hline $\begin{array}{l}\text { Midorikawa } \\
\text { et } \mathrm{al}^{27}\end{array}$ & J Hepatobiliary Pancreat Surg & $\begin{array}{l}\text { Retrospective } \\
\text { cohort study }\end{array}$ & Japan & $38 / 51$ & $63.8 \pm|1.2 / 6| .6 \pm \mid 1.2$ & $64 / 25$ & $2-60$ \\
\hline $\begin{array}{l}\text { Yamanaka } \\
\text { et } \mathrm{al}^{25}\end{array}$ & World J Surg & $\begin{array}{l}\text { Retrospective } \\
\text { cohort study }\end{array}$ & Japan & $27 / 23$ & $63 \pm 7.4 / 61 \pm 7.9$ & $37 / 13$ & $6-36$ \\
\hline
\end{tabular}

Note: An asterisk indicates one score of each section.

Abbreviations: MWA, microwave ablation; HRN, hepatic resection; BCLC, Barcelona Clinic Liver Cancer.

of timely studies (published within 10 years) and non-timely studies (published for more than 10 years), no inconsistent conclusions were found. The heterogeneity among studies was not significant $\left(I^{2}=0.0 \%, P=0.670\right)$. The funnel plot was applied for assessing publication bias of OS in studies in this meta-analysis (Figure 3). We did not identify any significant graphic and statistical bias by the rank correlation analysis (Begg's test) of funnel plot $(P=0.652)$.

\begin{tabular}{|c|c|c|}
\hline Study ID & HR (95\% Cl) & $\%$ weight \\
\hline \multicolumn{3}{|l|}{1} \\
\hline Takami et $a^{26}$ & $0.73(0.47,1.14)$ & 32.09 \\
\hline Li et $\mathrm{al}^{24}$ & $1.32(0.49,3.53)$ & 6.46 \\
\hline Zhang et $\mathrm{al}^{20}$ & $1.24(0.74,2.08)$ & 23.59 \\
\hline Shi et $\mathrm{al}^{22}$ & $1.12(0.70,1.79)$ & 28.58 \\
\hline Subtotal $\left(I^{2}=4.2 \%, P=0.372\right)$ & $1.00(0.77,1.30)$ & 90.71 \\
\hline \multicolumn{3}{|l|}{2} \\
\hline Yamanaka et $\mathrm{al}^{25}$ & $0.27(0.01,10.75)$ & 0.52 \\
\hline Horigome et $\mathrm{al}^{21}$ & $1.38(0.20,9.45)$ & 1.69 \\
\hline Midorikawa et al ${ }^{27}$ & $0.77(0.30,1.98)$ & 7.07 \\
\hline Subtotal $\left(I^{2}=0.0 \%, P=0.710\right)$ & $0.81(0.35,1.84)$ & 9.29 \\
\hline \multicolumn{3}{|c|}{ Heterogeneity between groups: $P=0.629$} \\
\hline Overall $\left(I^{2}=0.0 \%, P=0.670\right)$ & $0.98(0.76,1.26)$ & 100 \\
\hline
\end{tabular}

Figure 2 Forest plot of meta-analysis comparing the OS between MWA and HRN (pooled with HR).

Abbreviations: MWA, microwave ablation; OS, overall survival; HRN, hepatic resection. 


\begin{tabular}{|c|c|c|c|c|c|c|c|}
\hline \multirow{3}{*}{$\begin{array}{l}\text { Number of tumors } \\
\text { (MWA/HRN) }\end{array}$} & \multirow{3}{*}{$\begin{array}{l}\text { Tumor } \\
\text { size }(\mathrm{cm}) \\
\text { (MWA/HRN) }\end{array}$} & \multirow{3}{*}{$\begin{array}{l}\text { Associated } \\
\text { with cirrhosis } \\
\text { (MWA/HRN) }\end{array}$} & \multirow{3}{*}{$\begin{array}{l}\text { Tumor } \\
\text { stage } \\
\text { (BCLC) }\end{array}$} & \multicolumn{4}{|c|}{ Newcastle-Ottawa scale } \\
\hline & & & & & & & \\
\hline & & & & Total & Selection & Comparability & Outcome \\
\hline $1.017 \pm 0.02 / 1.126 \pm 0.05$ & $2.0 \pm 0.5 / 2.3 \pm 0.5$ & - & O/A & 7 & $* * * *$ & * & ** \\
\hline- & $2.7 \pm 0.3 / 2.7 \pm 0.4$ & - & O/A & 6 & $* * * *$ & - & $* *$ \\
\hline- & $3.8 \pm 0.9 / 3.6 \pm 0.7$ & & - & 6 & $* *$ & $* *$ & ** \\
\hline $1.191 \pm 0.04 / 1.178 \pm 0.04$ & - & $111 / 101$ & - & 8 & $* * *$ & $* *$ & $* * *$ \\
\hline $1.55 \pm 0.75 / I .1 I \pm 0.47$ & $2.08 \pm 0.5 / 2.23 \pm 0.7$ & - & O/A & 8 & $* * * *$ & $* *$ & $* *$ \\
\hline- & - & $96 / 71$ & - & 8 & $* * * *$ & $* *$ & $* *$ \\
\hline- & $1.7 \pm 0.6 / 2.3 \pm 0.7$ & - & - & 6 & $* * * *$ & - & $* *$ \\
\hline $1.9 \pm 1.12 / 1.53 \pm 1.05$ & $3.1 \pm 1.3 / 4.5 \pm 3.7$ & $31 / 36$ & - & 8 & $* * * *$ & $* *$ & ** \\
\hline $1.222 \pm 0.1 / 1.217 \pm 0.09$ & $3.3 \pm 1.5 / 3.1 \pm 1.8$ & $25 / 22$ & - & 6 & $* *$ & $* *$ & $* *$ \\
\hline
\end{tabular}

We further analyzed $\mathrm{HCC}<3 \mathrm{~cm}$, and there were no significant difference in OS between the MWA group and the HRN group $(\mathrm{HR}=0.95,95 \% \mathrm{CI}=0.70-1.30, P=0.758)$ (Figure 4A). The heterogeneity among studies was not significant $\left(I^{2}=0.0 \%, P=0.562\right)$. In the analysis of the treatment of PMCT compared with HRN, the OS was not statistically different $(\mathrm{HR}=1.25,95 \% \mathrm{CI}=0.76-2.06, P=0.383$ ) (Figure 4B). The heterogeneity among studies was very small $\left(I^{2}=0.0 \%, P=0.916\right)$.

We extracted the specific number of 3-year deaths in the original text and then pooled with OR. There were no notable difference in the MWA group and the HRN group $(\mathrm{OR}=1.05,95 \% \mathrm{CI}=0.67-1.66, P=0.824)$ (Figure 5).

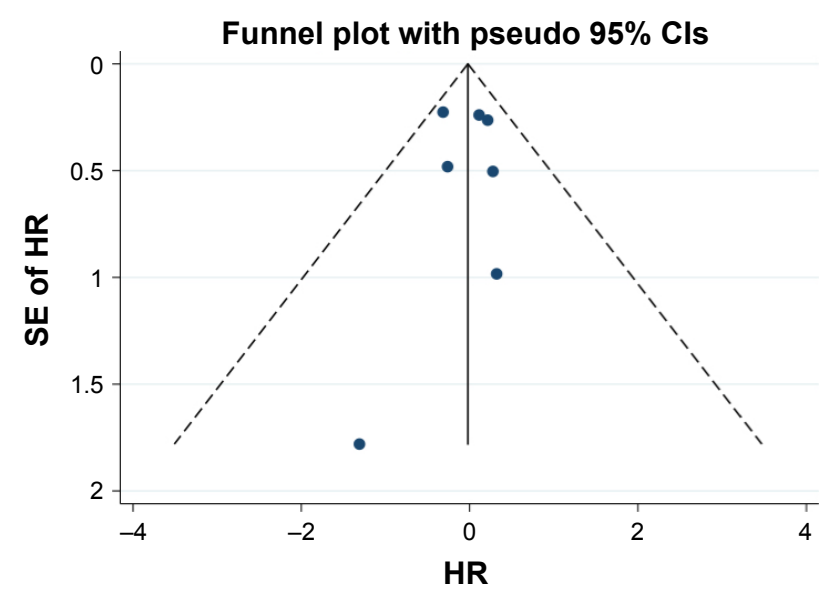

Figure 3 Funnel plot for assessing publication bias in OS.

Abbreviations: HR, hazard ratio; OS, overall survival; SE, standard error.
The heterogeneity among studies was not significant $\left(P^{2}=0.0 \%\right.$, $P=0.749$ ).

\section{Disease-free survival}

In total, 5 reports with available Kaplan-Meier curves were included for meta-analysis of DFS. The overall meta-analysis demonstrated that there was no diversity in DFS between the MWA group and the HRN group ( $\mathrm{HR}=1.16,95 \% \mathrm{CI}=0.79$ $1.71, P=0.442$ ) (Figure 6). The heterogeneity among studies was statistically significant $\left(I^{2}=71.1 \%, P=0.008\right)$. The funnel plot was applied for assessing publication bias of DFS in studies in this meta-analysis (Figure 7). We did not identify any significant statistical bias by the rank correlation analysis (Begg's test) of funnel plot $(P=1.000)$.

We further analyzed $\mathrm{HCC}<3 \mathrm{~cm}$, and there were no significant difference in DFS between the MWA group and the HRN group ( $\mathrm{HR}=1.46,95 \% \mathrm{CI}=0.98-2.17, P=0.062$ ) (Figure 8A). There appeared to be a certain degree of heterogeneity among studies $\left(I^{2}=36.7 \%, P=0.206\right)$. In the analysis of PMCT compared with HRN, the difference of DFS was not statistically significant $(\mathrm{HR}=0.72,95 \% \mathrm{CI}=0.5-1.02$, $P=0.068$ ) (Figure $8 \mathrm{~B}$ ). The heterogeneity among studies was not significant $\left(I^{2}=0.0 \%, P=0.894\right)$.

\section{Recurrence}

This meta-analysis showed that MWA would not increase the recurrence rate when compared with $\mathrm{HR}(\mathrm{OR}=1.11$, $95 \% \mathrm{CI}=0.77-1.61, P=0.573$ ) (Figure 9). The heterogeneity 

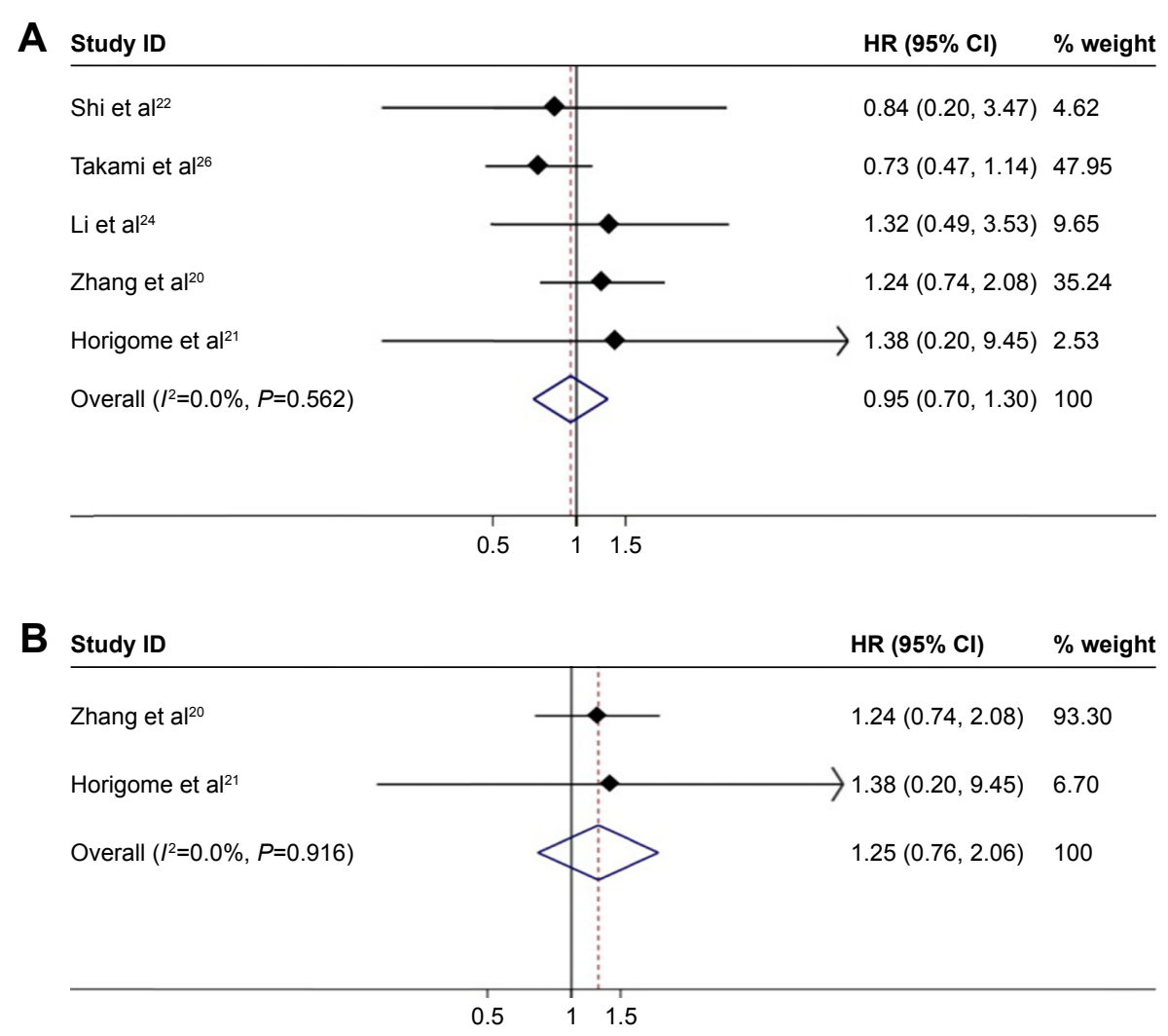

Figure 4 (A) Forest plot of meta-analysis comparing the OS between MWA and HRN (pooled with HR). Comparison of patients with HCC $<3 \mathrm{~cm}$. (B) Forest plot of meta-analysis comparing the OS between MWA and HRN (pooled with HR). Comparison of PMCT with HRN.

Abbreviations: HCC, hepatocellular carcinoma; MWA, microwave ablation; OS, overall survival; PMCT, percutaneous microwave coagulation therapy; HRN, hepatic resection.

among studies was not statistically significant $\left(I^{2}=20.4 \%\right.$; $P=0.285$ ).

\section{Secondary outcomes}

\section{Operation time and blood loss}

The surgical time of patients in the MWA group was obviously shorter than that in the HRN group (SMD $=-1.37,95 \%$ $\mathrm{CI}=-1.92$ to $-0.81, P=0.000$; Figure $10 \mathrm{~A})$, and the amount of intraoperative blood loss was also less in the MWA group. The differences were of statistical significance ( $\mathrm{SWD}=-1.19$, $95 \% \mathrm{CI}=-1.76$ to $-0.61, P=0.000$; Figure $10 \mathrm{~B})$.

\section{Complications}

Major complications were as follows: pleural effusion, pneumonia, atelectasis, ascites, wound infection, dehiscence, biliary leakage, hepatic encephalopathy, liver failure, persisting fever,

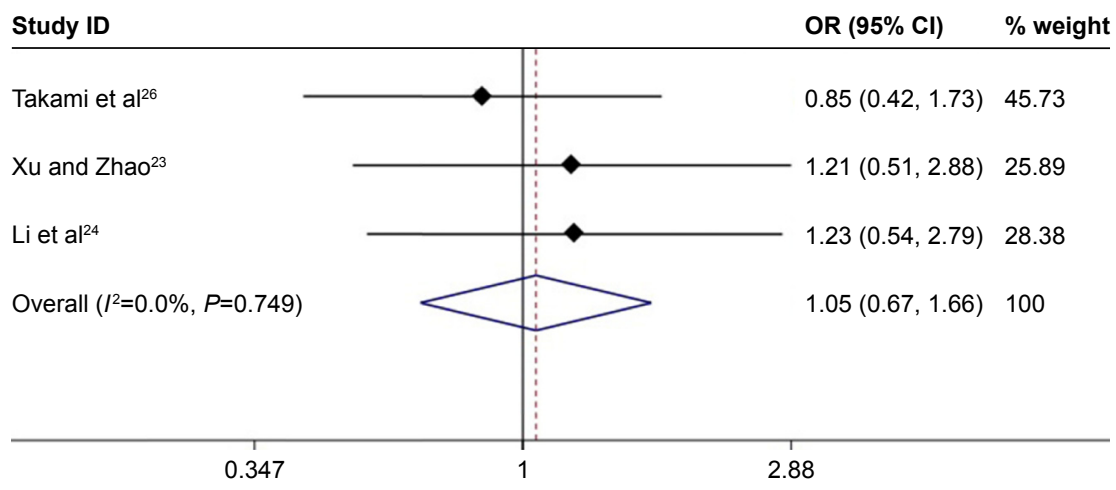

Figure 5 Forest plot of meta-analysis comparing the OS between MWA and HRN (pooled with OR).

Abbreviations: MWA, microwave ablation; OS, overall survival; HRN, hepatic resection. 


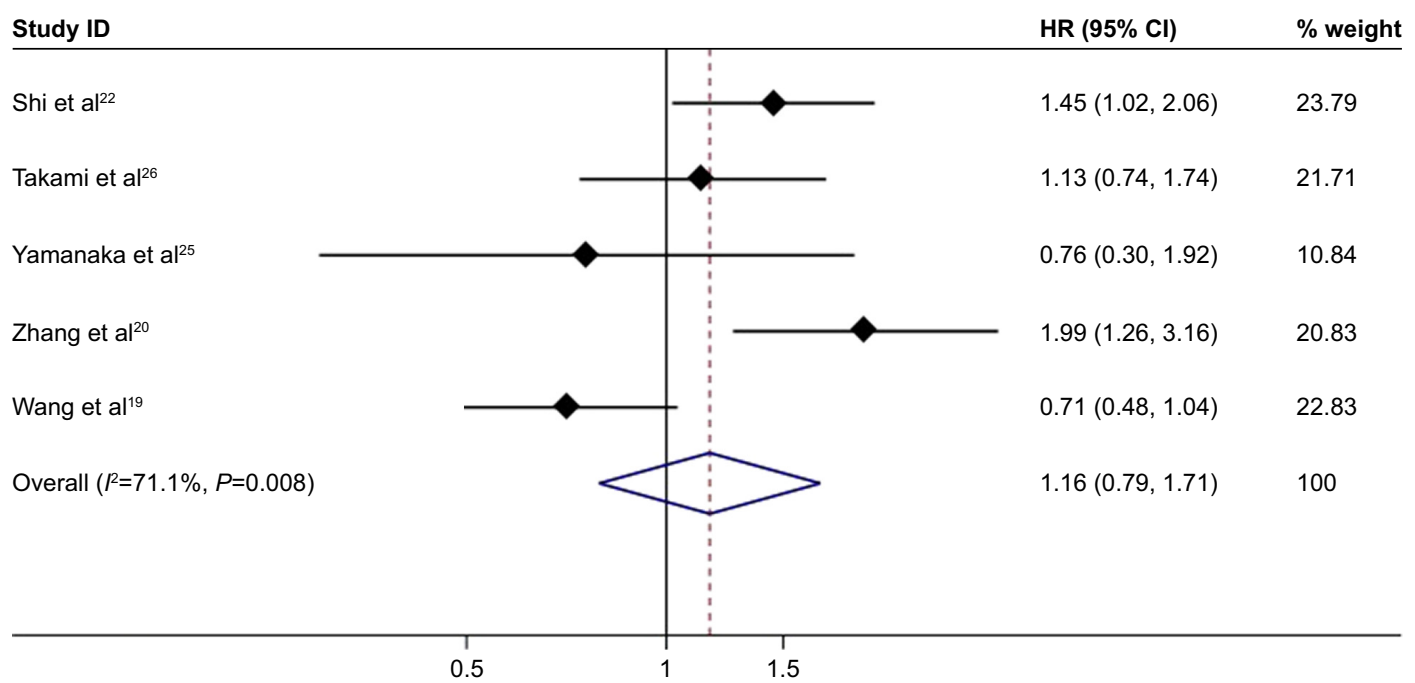

Figure 6 Forest plot of meta-analysis comparing the DFS between MWA and HRN (pooled with HR).

Note: Weights are from random effects analysis.

Abbreviations: DFS, disease-free survival; MWA, microwave ablation; HRN, hepatic resection.

gastric bleeding. Major complications were significantly more frequent in the HRN group than in the MWA group $(\mathrm{OR}=0.22$, $95 \% \mathrm{CI}=0.12-0.40, P=0.000$; Figure 10C).

\section{Discussion}

Meta-analysis has been recognized as an effective method to answer a wide variety of clinical questions by summarizing and reviewing previously published, quantitative research. The results from previous papers that compared the efficacy and safety of MWA and HRN in the treatment of HCC have been inconsistent. To the best of our knowledge, this is the first meta-analysis providing comprehensive insights into the effects of the MWA compared with HRN, which summarizes the results of 9 studies, with a total of 1,480 patients. The results indicate that overall, MWA is as effective as HRN in

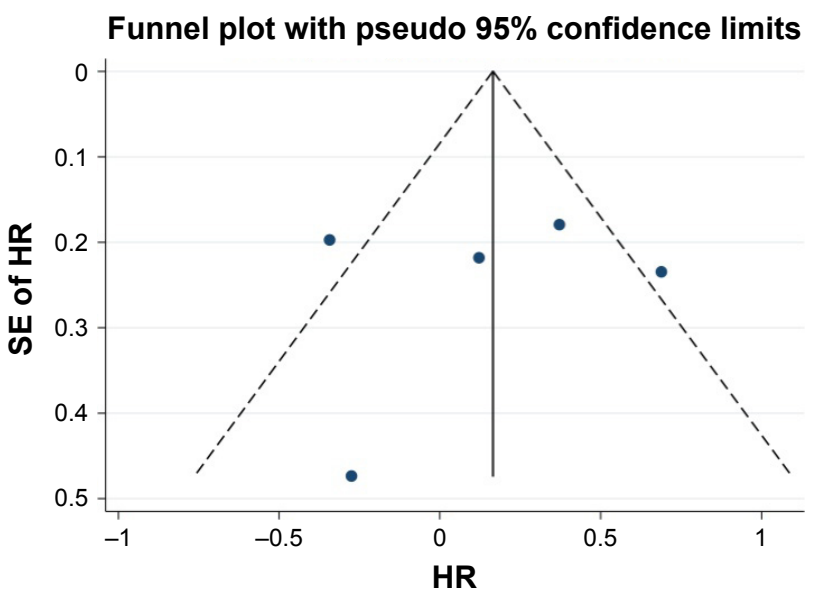

Figure 7 Funnel plot for assessing publication bias in DFS. Abbreviation: DFS, disease-free survival. terms of OS, DFS, recurrence rates in treating $\mathrm{HCC}$ of various sizes. Meanwhile, our study suggested that MWA was associated with shorter operation time, less amount of blood loss in operation, and less complications than HRN. MWA for the locoregional ablation of HCC has been used in Japan since 1988. In 1977, Tabuse $^{28}$ developed the microwave coagulator, Microtaze, to achieve hemostasis during HRN. In 1988, using this device, Saitsu et $\mathrm{al}^{29}$ systematically started to coagulate not only the hepatic parenchyma, but also the tumor itself, and first superior to percutaneous ethanol injection therapy for the local control of moderately or poorly differentiated small HCCs. However, since 1995, when RFA emerged, it has gained popularity worldwide. The recent improvement in ablation microwave technology has significantly improved clinical efficacy of this treatment, ${ }^{30}$ the potential advantages of MWA has been recognized, such as higher induced intratumoral temperatures, faster ablation time, larger ablation area, and less susceptibility to heat-sink effects.

According to the meta-analysis, we found that there was no difference in prognosis in tumors $<3 \mathrm{~cm}$ between MWA and HRN. Therefore, MWA deserves consideration for inclusion in HCC therapy in Clinical Practice Guidelines for small HCC. We believe that MWA can be applied as first ablative choice treatment in small HCC, at least in patients with severe cirrhosis or portal hypertension; patients with comorbidities that cannot tolerate operation; and patients with deeply located tumors or multiple lesions.

The reasons for the comparable effectiveness in terms of the OS and DFS may be as follows: MWA reduced liver damage and preserved normal liver tissues to the maximum 


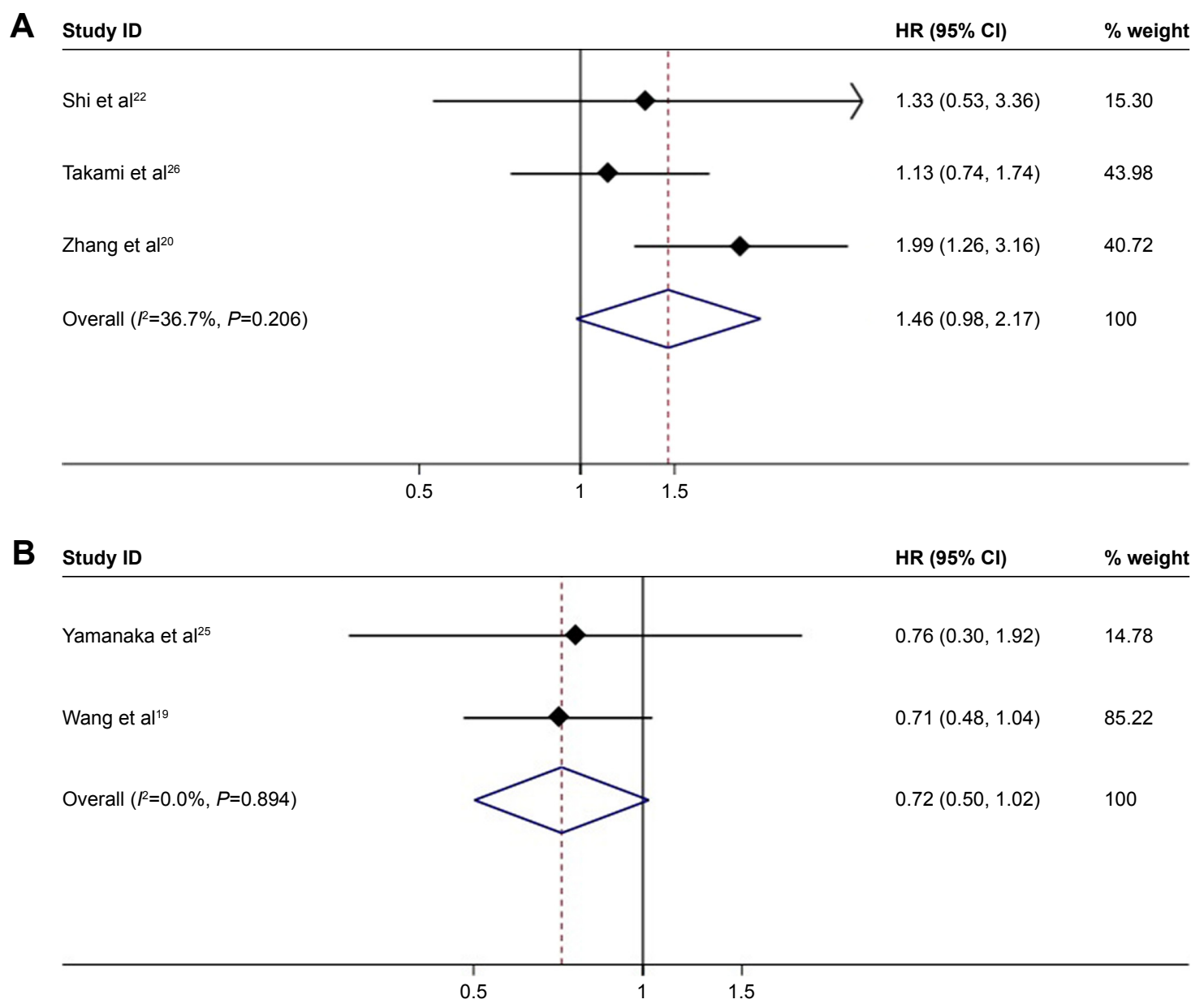

Figure 8 (A) Forest plot of meta-analysis comparing the DFS between MWA and HRN (pooled with HR). Comparing the patients with HCC smaller than $3 \mathrm{~cm}$. Weights are from random effects analysis. (B) Forest plot of meta-analysis comparing the DFS between MWA and HRN (pooled with HR). Comparing PMCT with HRN.

Abbreviations: DFS, disease-free survival; HCC, hepatocellular carcinoma; MWA, microwave ablation; PMCT, percutaneous microwave coagulation therapy; HRN, hepatic resection.

\begin{tabular}{|c|c|c|}
\hline Study ID & OR (95\% Cl) & $\%$ weight \\
\hline Wang et al ${ }^{19}$ & $0.73(0.38,1.41)$ & 40.36 \\
\hline $\mathrm{Xu}$ and $\mathrm{Zhao}{ }^{23}$ & $1.20(0.52,2.74)$ & 19.29 \\
\hline Shi et $\mathrm{al}^{22}$ & $1.45(0.84,2.51)$ & 40.35 \\
\hline Overall $(P=20.4 \%, P=0.285)$ & $1.11(0.77,1.61)$ & 100 \\
\hline
\end{tabular}

Figure 9 Forest plot of meta-analysis comparing the tumor recurrence between MWA and HRN (pooled with OR).

Abbreviations: MWA, microwave ablation; HRN, hepatic resection. 


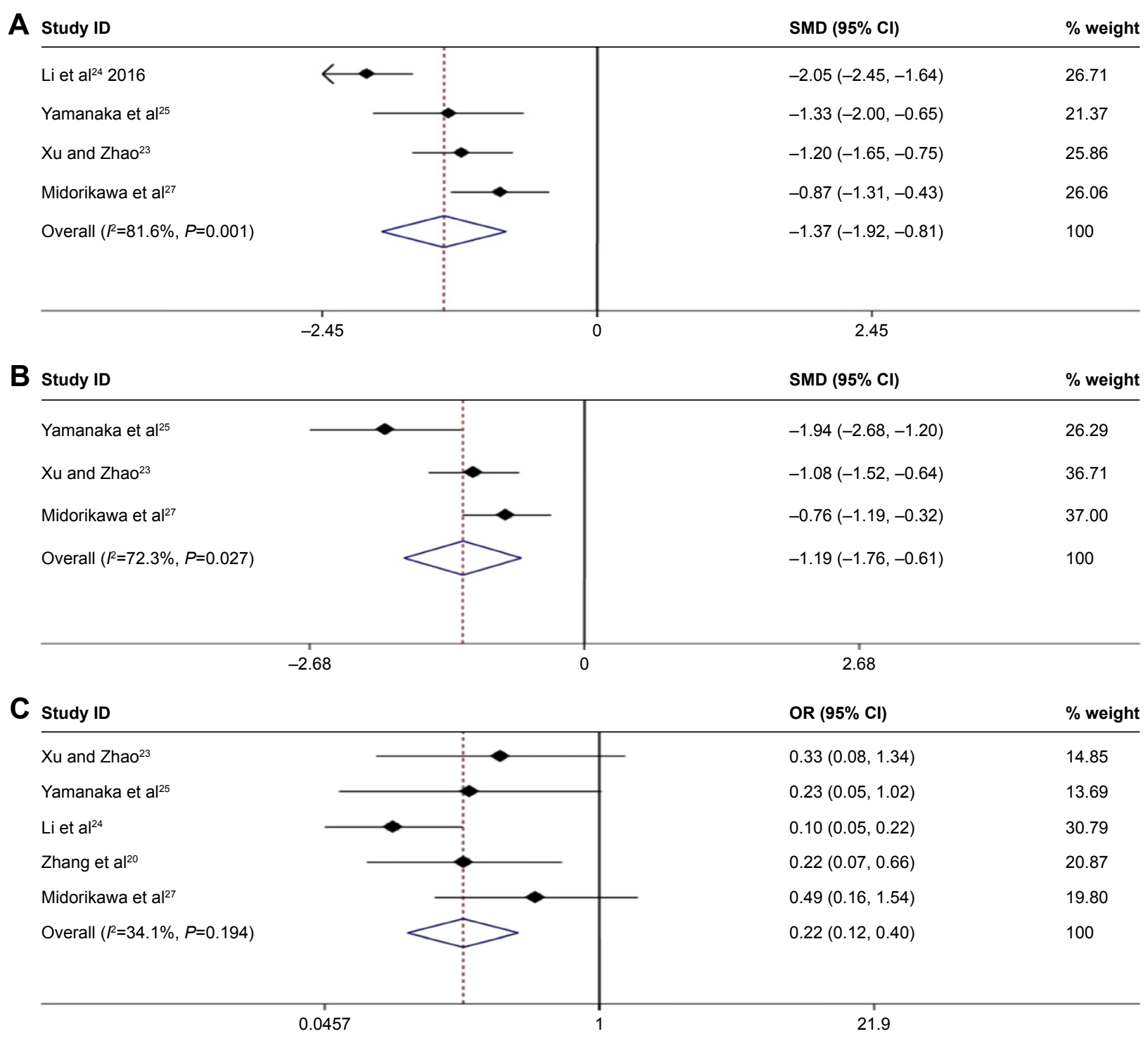

Figure 10 (A) Forest plot of meta-analysis comparing operation time between MWA and HRN. (B) Forest plot of meta-analysis comparing blood loss between MWA and HRN. (C) Forest plot of meta-analysis comparing complication between MWA and HRN. Weights are from random effects analyses.

Abbreviations: MWA, microwave ablation; SMD, standardized mean difference; HRN, hepatic resection.

extent, with less impact on liver function. ${ }^{31}$ In addition, MWA was easier to implement for lesions located in the center of the liver.

On the other hand, our study suggested that MWA was associated with shorter operation time, less blood loss, and fewer complications compared with HRN. MWA can be performed with minimal invasiveness. Therefore, MWA has a considerable advantage over HRN in providing a better short-term post-operative result.

Some limitations in our meta-analysis should be mentioned. First, the papers included in this meta-analysis were insufficient, thus, potential publication bias is very likely to exist, although there is no evidence obtained from our statistical tests. Second, the language of studies was limited to English, which could lead to potential language bias. Third, since most studies are observational cohort, there is a possibility of patient selection bias. Fourth, the HR we pooled was not directly provided in the articles, there may be a part of the possibility of deviation. Finally, only 2 comparative studies with regard to the efficacy between PMCT and HRN could not reach definitive conclusion; further studies would be required to confirm the results.

\section{Conclusion}

Our meta-analysis suggests that MWA may be superior to HRN as it is as effective as HRN in terms of OS, DFS, 
recurrence rates, and associated with shorter operation time, less amount of blood loss in operation, and fewer complications. However, multi-center, prospective and large randomized controlled trials are required to confirm our findings.

\section{Acknowledgments}

This study was supported by the National Major Scientific and Technological Project during the Twelfth 5-year Plan Period (No 2014ZX10005002-002), Special Research Project of Traditional Chinese Medicine Industry (No 201507005) and Capital Project of Science and Technology Development of Traditional Chinese Medicine in Beijing (No JJ2015-72).

\section{Disclosure}

The authors report no conflicts of interest in this work.

\section{References}

1. Jemal A, Bray F, Melissa M, Ferlay J, Ward E, Forman D. Global cancer statistics. CA Cancer J Clin. 2011;61(2):69-90.

2. Torre L.A, Bray F, Rebecca L, Ferlay J, Lortet-Tieulent J, Jemal A. Global cancer statistics, 2012. CA Cancer J Clin. 2015;65(2):87-108.

3. Wong R, Frenette C. Updates in the management of hepatocellular carcinoma. Gastroenterol Hepatol (N Y). 2011;7(1):16-24.

4. Ishizawa T, Hasegawa K, Aoki T, et al. Neither multiple tumors nor portal hypertension are surgical contraindications for hepatocellular carcinoma. Gastroenterology. 2008;134(7):1908-1916.

5. Gravante G, Overton J, Sorge R, et al. Radiofrequency ablation versus resection for liver tumours: an evidence-based approach to retrospective comparative studies. J Gastrointest Surg. 2011;15(2):378-387.

6. Liang P, Wang Y. Microwave ablation of hepatocellular carcinoma. Oncology. 2007;72(Suppl 1):124-131.

7. Vergara Gómez M, Miquel Planas M, Gil Prades M, et al. [Rapid progression of hepatocellular carcinoma after surgery: apropos of a case and review of the literature]. Gastroenterol Hepatol. 2010;33(8): 569-573. Spanish.

8. Brace CL. Radiofrequency and microwave ablation of the liver, lung, kidney, and bone: what are the differences? Curr Probl Diagn Radiol. 2009;38(3):135-143.

9. Shiozawa K, Watanabe M, Takahashi M, Wakui N, Iida K, Sumino Y. Analysis of patients with rapid aggressive tumor progression of hepatocellular carcinoma after percutaneous radiofrequency ablation. Hepatogastroenterology. 2009;56(96):1689-1695.

10. Simon CJ, Dupuy DE, Mayo-Smith WW, et al. Microwave ablation: principles and applications. Radiographics. 2005;25(Suppl 1): S69-S83.

11. Kim HJ, Rhim H, Lee MW, Jeong WK. Measurement of intrahepatic pressure during microwave ablation in an ex vivo bovine liver model. Gut Liver. 2015;9(6):784-790.

12. Laeseke PF, Lee FT Jr, Sampson LA, van der Weide DW, Brace CL. Microwave ablation versus radiofrequency ablation in the kidney: high-power triaxial antennas create larger ablation zones than similarly sized internally cooled electrodes. $J$ Vasc Interv Radiol. 2009;20(9): 1224-1229.
13. Lu MD, Chen JW, Xie XY, et al. Hepatocellular carcinoma: US-guided percutaneous microwave coagulation therapy. Radiology. 2001; 221(1):167-172.

14. Dong BW, Liang P, Yu XL, et al. Sonographically guided microwave coagulation treatment of liver cancer: an experimental and clinical study. AJR Am J Roentgenol. 1998;171(2):449-454.

15. Stang A. Critical evaluation of the Newcastle-Ottawa scale for the assessment of the quality of nonrandomized studies in meta-analyses. Eur J Epidemiol. 2010;25(9):603-605.

16. Moher D, Liberati A, Tetzlaff J, et al. Preferred reporting items for systematic reviews and meta-analyses: the PRISMA statement. Open Med. 2009;3(3):e123-e130.

17. Parmar MK, Torri V. Extracting summary statistics to perform metaanalyses of the published literature for survival endpoints. Stat Med. 1998;17(24):2815-2834.

18. Wang Y, Zeng T. Response to: practical methods for incorporating summary time-to-event data into meta-analysis. Trials. 2013;14(1):391.

19. Wang ZL, Liang P, Dong BW, Yu XL, Yu DJ. Prognostic factors and recurrence of small hepatocellular carcinoma after hepatic resection or microwave ablation: a retrospective study. J Gastrointest Surg. 2008; 12(2):327-337.

20. Zhang EL, Yang F, Wu ZB, et al. Therapeutic efficacy of percutaneous microwave coagulation versus liver resection for single hepatocellular carcinoma $\leq 3 \mathrm{~cm}$ with Child-Pugh A cirrhosis. Eur J Surg Oncol. 2016;42(5):690-697.

21. Horigome H, Nomura T, Nakao H, et al. Treatment of solitary small hepatocellular carcinoma: consideration of hepatic functional reserve and mode of recurrence. Hepatogastroenterology. 2000;47(32): 507-511.

22. Shi J, Sun Q, Wang Y, et al. Comparison of microwave ablation and surgical resection for treatment of hepatocellular carcinomas conforming to Milan criteria. J Gastroenterol Hepatol. 2014;29(7):1500-1507.

23. Xu J, Zhao Y. Comparison of percutaneous microwave ablation and laparoscopic resection in the prognosis of liver cancer. Int J Clin Exp Pathol. 2015;8(9):11665.

24. Li W, Zhou X, Huang Z, et al. Short- and long-term outcomes of laparoscopic hepatectomy, microwave ablation and open hepatectomy for small hepatocellular carcinoma: a 5-year experience in a single center. Hepatol Res. 2017;47(7):650-657.

25. Yamanaka N, Tanaka T, Oriyama T, et al. Microwave coagulonecrotic therapy for hepatocellular carcinoma. World J Surg. 1996;20(8): 1076-1081.

26. Takami Y, Ryu T, Wada Y, et al. Evaluation of intraoperative microwave coagulonecrotic therapy $(\mathrm{MCN})$ for hepatocellular carcinoma: a single center experience of 719 consecutive cases. J Hepatobiliary Pancreat Sci. 2013;20(3):332-341.

27. Midorikawa T, Kumada K, Kikuchi H, et al. Microwave coagulation therapy for hepatocellular carcinoma. J Hepatobiliary Pancreat Surg. 2000;7(3):252-259.

28. Tabuse K. A new operative procedure of hepatic surgery using a microwave tissue coagulator. Nihon Geka Hokan. 1979;48(2):160-172.

29. Saitsu H, Yoshida M, Taniwaki S, et al. Laparoscopic coagulo-necrotic therapy using Microtase for small hepatocellular carcinoma. Nihon Shokakibyo Gakkai Zasshi. 1991;88(10):2727.

30. Poggi G, Tosoratti N, Montagna B, Picchi C. Microwave ablation of hepatocellular carcinoma. World J Hepatol. 2015;7(25):2578-2589.

31. Poulou LS, Botsa E, Thanou I, et al. Percutaneous microwave ablation vs radiofrequency ablation in the treatment of hepatocellular carcinoma. J World J Hepatol. 2015;7(8):1054-1063. 
OncoTargets and Therapy

\section{Publish your work in this journal}

OncoTargets and Therapy is an international, peer-reviewed, open access journal focusing on the pathological basis of all cancers, potential targets for therapy and treatment protocols employed to improve the management of cancer patients. The journal also focuses on the impact of management programs and new therapeutic agents and protocols on The manuscript management system is completely online and includes a very quick and fair peer-review system, which is all easy to use. Visit http://www.dovepress.com/testimonials.php to read real quotes from published authors.

Submit your manuscript here: http://www.dovepress.com/oncotargets-and-therapy-journal 